\title{
Practical Islamic and Research Ethics: The Use of Animal Model in Orthopaedic Research
}

Nurul Hafiza Mohd Jan, Ahmad Hafiz Zulkifly, Mohd Zulfadzli Ibrahim

Department of Orthopaedic, Traumatology and Rehabilitation, Kulliyyah of Medicine, International Islamic University Malaysia, Kuantan Pahang.

Introduction: The growing of mortality and morbidity that are related to orthopaedic cases have contributed to the development and innovation of technology which actively seeks for the best treatment options. In order to achieve the goal, animal models have been used as a bridge from in vitro to the clinical study to provide insights both as a precursor and beneficial to human-based research. Many animal models have been developed to investigate bone regeneration, pathological changes and reparation. Besides, animal models are used more commonly in orthopaedic innovation and development. Through the practical application of the 5Rs (reduction, refinement, replacement, reproducibility and responsibility) principles that correlate with the Islamic ethics in this research, this study aimed to provide an ultimate ethical standard on animal use in orthopaedic research. Besides the texts of the Qur'an and the prophetic narrations (hadith), both Muslim jurists (fuqaha) and ethicists' relevant opinion on these matters would be unveiled. As from the Islamic viewpoints, the usage of animal is permittable for scientific research purposed within the permissible limits described by the Shari'ah and guided by ethical values derived from the Divine Revelations (al-wahy al-Ilahyi). By practising the guidelines, it is hoped that these ethical guidelines will help to educate the Muslim scholars and researchers to substantive improvements in terms of quality and the ethical standards of animal studies in orthopaedic research. 